\title{
Obstetric hysterectomy: a retrospective study at a tertiary care centre
}

\author{
Anjali Kanhere*, Rekha Sapkal
}

Department of Obstetrics and Gynecology, PCMS \& RC, Bhopal, Madhya Pradesh, Pin 462044, India

Received: 24 September 2013

Accepted: 5 October 2013

\author{
*Correspondence: \\ Dr. Anjali Kanhere, \\ E-mail: kanhereanju@yahoo.com
}

(C) 2013 Kanhere A et al. This is an open-access article distributed under the terms of the Creative Commons Attribution Non-Commercial License, which permits unrestricted non-commercial use, distribution, and reproduction in any medium, provided the original work is properly cited.

\begin{abstract}
Background: To analyze the cases of Obstetric Hysterectomy in view to evaluate the incidence, indication, maternal risk factors and complications associated with the surgery.

Methods: Retrospective Observational analytical study of cases of obstetric hysterectomy performed at Obstetrics and Gynecology department of People's Medical College and Research Centre, Bhanpur, Bhopal over a period of seven years was done. Evaluation of Maternal age, parity, gestational age, indication for hysterectomy, the type of operation performed, blood loss, blood transfused, complications, and hospitalization period was done.

Results: The overall incidence of Obstetric hysterectomy in our study was found to be $0.33 \%$, with a maximum number of patients 7 (33\%) in the age group of 26-30 yrs. Patients who were para 3 or more were $-12(63 \%)$. The causes for an obstetric hysterectomy were PPH - 12 (63\%); placenta previa $-5(26 \%)$; ruptured uterus $-4(21 \%)$. $9(47 \%)$ patients had a history of previous caesarean section. Out of the 19 hysterectomies performed, 12(63\%) were total hysterectomy and 7(37\%) were subtotal hysterectomy. Fever was the commonest complication 7(37\%). There were two maternal deaths.

Conclusions: Obstetric hysterectomy is a lifesaving procedure. The outcome depends on timely decision, good clinical judgement and professional surgical technique. It reduces maternal morbidity and mortality.
\end{abstract}

Keywords: Obstetric hysterectomy, Postpartum haemorrhage, Rupture uterus, Previous caesarean section

\section{INTRODUCTION}

Obstetric hysterectomy is the removal of uterus at the time of caesarean section, following caesarean section, immediately after vaginal delivery or in the period of puerperium. ${ }^{1}$

Obstetric hysterectomy is usually the last resort in the obstetrician's armamentarium to save the life of the mother. ${ }^{2}$ In developing countries obstetric haemorrhage is the leading cause of maternal deaths. ${ }^{3}$ Prompt decision making and excellent surgical skills with a speedy intervention are the key component of this life saving procedure. Early resuscitation, transfusion of blood and blood components helps to improve deteriorating haemodynamic parameters and helps the patient to withstand the surgical procedure and anaesthesia.
The commonest indications for emergency hysterectomy which are cited in the literature are uterine rupture and atonic uterus. ${ }^{4} \mathrm{With}$ increase in the number of caesarean deliveries abnormal placenta adhesions, Placenta Previa has emerged as the most common indication for this operation in developed countries. This change in trend is being seen in developing countries as well. ${ }^{2,6}$

The purpose of our study was to analyze the cases of Obstetric Hysterectomy in view to evaluate the incidence, indication, maternal risk factors and complications associated with the surgery.

\section{METHODS}

Retrospective Observational analytical study of 19 cases of obstetric hysterectomy performed at Obstetrics and Gynecology department of People's Medical College and 
Research Centre, Bhanpur, Bhopal over a period of seven years was done. Evaluation of maternal age, parity, gestational age, indication for hysterectomy, the type of operation performed, estimated blood loss, amount of blood and components transfused, complications, and hospitalization period was done. The foetal outcome was also analysed.

\section{RESULTS}

During the study period of Seven years total number of deliveries were 6735 , of which vaginal deliveries were 3451 and LSCS were3284.The overall incidence of obstetric hysterectomy was $0.28 \%, 0.08 \%$ was in cases of vaginal delivery and $0.46 \%$ was in cases of LSCS for various indications.

Maternal Characteristics - Age and Parity-Age of patients ranges from 22-38 (mean age $\approx 29$ ). Seven patient $37 \%$ were in the age group of 26 to 30yearsand were multipara (parity > 4). This shows that the incidence of this radical and lifesaving surgery is more in this group.

Antenatal Booking-Fourteen patients (74\%) were unbooked and fifteen patients (79\%) were from rural area.

Indications- The commonest indication for performing obstetric hysterectomy was postpartum haemorrhage $12(63 \%)$ followed by placenta previa $5(26 \%)$ and rupture uterus $4(21 \%)$.

Previous caesarean section was a significant high risk factor 9(47\%), all placenta previa was associated with previous caesarean section $100 \%$.

Type of hysterectomy and associated surgical procedure - Out of the 19 hysterectomies performed, 12 were total hysterectomy and 7 were subtotal.3patients underwent internal iliac artery ligation prior to hysterectomy. 1 patient underwent bowel repair.

Postoperative complication - Postoperative shock, paralytic ileus and fever were the common complications.

Blood loss and blood transfusion - The average blood loss was in the range of 2 to 3 litres. All patients underwent replacement therapy with blood and component transfusion.

Hospital Stay - 12(63\%) had hospital stay of around 25 days.

There were two maternal deaths $(11 \%)$ in patients with associated medical complication of jaundice and uncontrolled diabetes mellitus.
Foetal characteristics: There were 12 live births with average birth weight of $2.6 \mathrm{kgs}$. Two out of the total were preterm and died in neonatal period, another two were stillbirths, and three were intrauterine deaths. The proportion of perinatal mortality was $37 \%$.

Table 1: Age wise distribution of cases of obstetric hysterectomy.

\begin{tabular}{|lll|}
\hline Age (years) & $\begin{array}{l}\text { Number of } \\
\text { patient }\end{array}$ & Percentage \\
\hline $21-25$ & 6 & 32 \\
\hline $26-30$ & 7 & 37 \\
\hline $31-35$ & 5 & 26 \\
\hline $36-40$ & 1 & 5 \\
\hline Total & 19 & 100 \\
\hline
\end{tabular}

Table 2: Indications of obstetric hysterectomy.

\begin{tabular}{|lll|}
\hline Indication & $\begin{array}{l}\text { Number of } \\
\text { patients }\end{array}$ & Percentage \\
\hline $\begin{array}{l}\text { PPH without } \\
\text { placenta previa }\end{array}$ & 06 & $6 / 19$ \\
\hline Placenta Previa & 05 & $5 / 19$ \\
\hline Rupture uterus & 04 & $4 / 19$ \\
\hline Puerperal sepsis & 02 & $2 / 19$ \\
\hline $\begin{array}{l}\text { Perforation during } \\
\text { termination of } \\
\text { pregnancy }\end{array}$ & 01 & $1 / 19$ \\
\hline \begin{tabular}{l} 
Acute inversion \\
\hline
\end{tabular} & 01 & $1 / 19$ \\
\hline
\end{tabular}

Table 3: High risk factors (figure in bracket shows number of patients).

\begin{tabular}{|lll|}
\hline PPH(12) & $\begin{array}{l}\text { Rupture } \\
\text { Uterus (4) }\end{array}$ & $\begin{array}{l}\text { Morbidly } \\
\text { adherent } \\
\text { placenta (5) }\end{array}$ \\
\hline $\begin{array}{l}\text { Placenta } \\
\text { Previa (5) }\end{array}$ & $\begin{array}{l}\text { Previous } \\
\text { Caesarean } \\
\text { section (9) }\end{array}$ & $\begin{array}{l}\text { Placenta Previa } \\
\text { (5) }\end{array}$ \\
\hline $\begin{array}{l}\text { Prolonged } \\
\text { Labour (3) }\end{array}$ & $\begin{array}{l}\text { Grand } \\
\text { multipara (3) }\end{array}$ & $\begin{array}{l}\text { Previous } \\
\text { Caesarean } \\
\text { section (9) }\end{array}$ \\
\hline $\begin{array}{l}\text { Multiple } \\
\text { pregnancy (2) }\end{array}$ & $\begin{array}{l}\text { Prolonged } \\
\text { labour (3) }\end{array}$ & \\
\hline $\begin{array}{l}\text { Polyhydramnios } \\
\text { (1) }\end{array}$ & & \\
\hline Postdatism (1) & & \\
\hline
\end{tabular}


Table 4: Associated complications (figure in bracket shows number of patients).

\begin{tabular}{|ll|}
\hline $\begin{array}{l}\text { Medical } \\
\text { complications }\end{array}$ & $\begin{array}{l}\text { Obstetric } \\
\text { complications }\end{array}$ \\
\hline Rh-ve (1) & Prolonged labour (3) \\
\hline Diabetes Mellitus (1) & Multiple pregnancy (2) \\
\hline Liver Disease (2) & Placenta Previa (5) \\
\hline PIH(4) & Polyhydramnios (1) \\
\hline Sepsis(2) & Postdatism (1) \\
\hline
\end{tabular}

\section{DISCUSSION}

Obstetric hysterectomy is a lifesaving procedure. Prompt decision and good surgical skills are the two factors related with surgeon's acumen that affect the maternal outcome. ${ }^{7}$ The present study was done to evaluate the incidence, indication, maternal risk factors and complications associated with the surgery.

In our study the incidence of Obstetric hysterectomy was $0.28 \%$. The incidence was in the same range as reported by Kant et al. ${ }^{3}$ The primary reason for this incidence is due to the fact that our institution is a tertiary referral center and receive patients from periphery.

Seven patient $37 \%$ were in the age group of 26 to 30years and were multipara (parity > 4).High association with multiparty was seen by Najam R et al. ${ }^{2}$ This observation highlights the need of emphasis on usage of contraceptive methods and counselling

The commonest indication of obstetric hysterectomy in our study was postpartum hemorrahge12 $(63 \%)$ followed by placenta previa $5(26 \%)$ and rupture uterus 4(21\%).Similar findings have being reported by Kant et al $(41.46 \%)$ and Agashe and Marathe $(60 \%){ }^{8}$

The dangerous combination of previous caesarean section, morbid adherent placenta and placenta previa was seen in our series. This is highlighted in other studies also. ${ }^{6,9,10}$ It is reported in the literature ${ }^{11}$, the incidence of obstetrical hysterectomy due to uterine atony shows a decline from $42 \%$ to $29 \%$ while the incidence has increased from $25 \%$ to $41 \%$ due to abnormal placentation. This is due to increased incidence of abnormal placental insertion, invasion anomalies associated with increased rate of caesarean section.Use of uterotonics and hemostatic agents along with use of other surgical technique like internal iliac artery ligation does not avert the need of obstetric hysterectomy in these cases.

Preoperative hemoglobin and hematocrit levels were in a low range of 5.0-8.0 gm/dl. This resulted in fresh blood transfusion and blood components. ${ }^{2}$
Postoperative shock, paralytic ileus and fever were the common complications. ${ }^{12}$

The maternal mortality rate in our study was $11 \%$ with DIC and septicaemia being the attributing causes. Kanwar et $\mathrm{al}^{13}$ reported this as $12 \%$ and Siddiq et al of $9.7 \% .^{14}$ Praneswari Devi et al reported no mortality in their studies. ${ }^{15}$ Perinatal mortality was $37 \%$.

\section{CONCLUSIONS}

Obstetric hysterectomy is a lifesaving procedure. The outcome depends on timely decision, good clinical judgement and professional surgical technique. It reduces the maternal morbidity and mortality.

Proper antenatal care, identification of high risk cases, patient \& relative counselling, and timely referral can prevent the incidence of this catastrophic surgery. Every obstetrician should learn to perform Obstetric hysterectomy. Judicious use of this skill can help in reducing the maternal morbidity and mortality.

\section{Funding: None}

Conflict of interest: None declared

Ethical approval: The study was approved by the Institutional Ethics Committee

\section{REFERENCES}

1. McNulty JV. Elective caesarean hysterectomy revisited. Am J Obstet Gynaecol 1984; 149: 29-32.

2. Najam R, Bansal P, Sharma R, Agrawal D. Emergency Obstetric Hysterectomy: A retrospective study at a tertiary care hospital. Journal of Clinical and Diagnostic Research 2010;4:2864-2868.

3. Anita K, Kavita WW. Emergency obstetric hysterectomy. J Obstet Gynecol India 2005 MarApr; 55(2): 132-4.

4. Chestnut DH, Eden RD, Gall SA, Parker RT. Peripartum hysterectomy: A review of cesarean and postpartum hysterectomy. Obstet Gynecol 1985; 65:365-70.

5. Zelop CM, Harlow BL, Frigoletto FD, Safon LE, Saltzman Dh. Emergency peripartum hysterectomy. Am J Obstet Gynecol 1993; 168:1443-1445.

6. Korejo R, Bhutta S, Nasir A, Yasmin H. Emergency Obstetric Hysterectomy. JPMA 62:Dec 2012;13221325.

7. Clark SL, Yeh SY, Phelan JP, Bruce S, Paul RH. Emergency hysterectomy for obstetrical hemorrhage. Obstet Gynecol 1984; 64: 376-80.

8. Agashe A P, Marathe SS. Obstetric hysterectomy (A review of 50 cases from January 1987 to August 1990). J Obstet Gynecol India 1991;45:490-3.

9. Bakshi S, Meyer BA. Indications for and outcomes of emergency peripartum hysterectomy. A 5-year review. J Reprod Med 2000; 45: 733-7. 
10. Francois K, Ortiz J, Harris C, Foley MR, Elliott JP. Is peripartum hysterectomy more common in multiple gestations? Obstet Gynaecol 2005; 105: 1369-72.

11. Zorlu CG, Turan C, Isik AZ, Danisman N, Mungan $\mathrm{T}$, Gokmen O. Emergency hysterectomy in modern obstetric practice. Changing clinical perspective in time. Acta Obstet Gynaecol Scand 1998;77:186-90.

12. Vázquez JA, Rivera GV, Higareda SH, Páez FG, Vega CC, Segura AP. Obstetric hysterectomy. Incidence, indications and complications. Ginecol Obstet Mex. 2008; 76(3):156-60.
13. Kanwar M, Sood PL, Gupta KB, et al. Emergency hysterectomy in obstetrics. J Obstet Gynecol India 2003; 53: 350-2.

14. Siddiq N, Ghazi A, Jabbar S, Ali T. Emergency Obstetrical Hysterectomy (EOH): A Life saving procedure in obstetrics. Pakistan J surgery 2007; 23(3): 217-9.

15. Devi P, Singh RK, Singh D. Emergency Obstetric hysterectomy. J Obstet Gynecol India 2004;54:3435 .

DOI: $10.5455 / 2320-1770 . i j r \operatorname{cog} 20131214$

Cite this article as: Kanhere A, Sapkal R.

Obstetric hysterectomy: a retrospective study at a tertiary care centre. Int J Reprod Contracept Obstet

Gynecol 2013;2:562-5. 